\title{
Levels and Causes of Stress, Anxiety and Depression among Road Transport Department Malaysia Headquarters Staffs
}

\author{
Wong, B. Y. \& Subhi, N.
}

To Link this Article: http://dx.doi.org/10.6007/IJARBSS/v12-i1/12105

DOI:10.6007/IJARBSS/v12-i1/12105

Received: 16 November 2021, Revised: 20 December 2021, Accepted: 30 December 2021

Published Online: 14 January 2022

In-Text Citation: (Wong \& Subhi, 2022)

To Cite this Article: Wong, B. Y., \& Subhi, N. (2022). Levels and Causes of Stress, Anxiety and Depression among Road Transport Department Malaysia Headquarters Staffs. International Journal of Academic Research in Business and Social Sciences, 12(1), $854-865$.

\section{Copyright: (c) 2022 The Author(s)}

Published by Human Resource Management Academic Research Society (www.hrmars.com)

This article is published under the Creative Commons Attribution (CC BY 4.0) license. Anyone may reproduce, distribute, translate and create derivative works of this article (for both commercial and non0-commercial purposes), subject to full attribution to the original publication and authors. The full terms of this license may be seen at: http://creativecommons.org/licences/by/4.0/legalcode

\section{Vol. 12, No. 1, 2022, Pg. $854-865$}

Full Terms \& Conditions of access and use can be found at http://hrmars.com/index.php/pages/detail/publication-ethics 


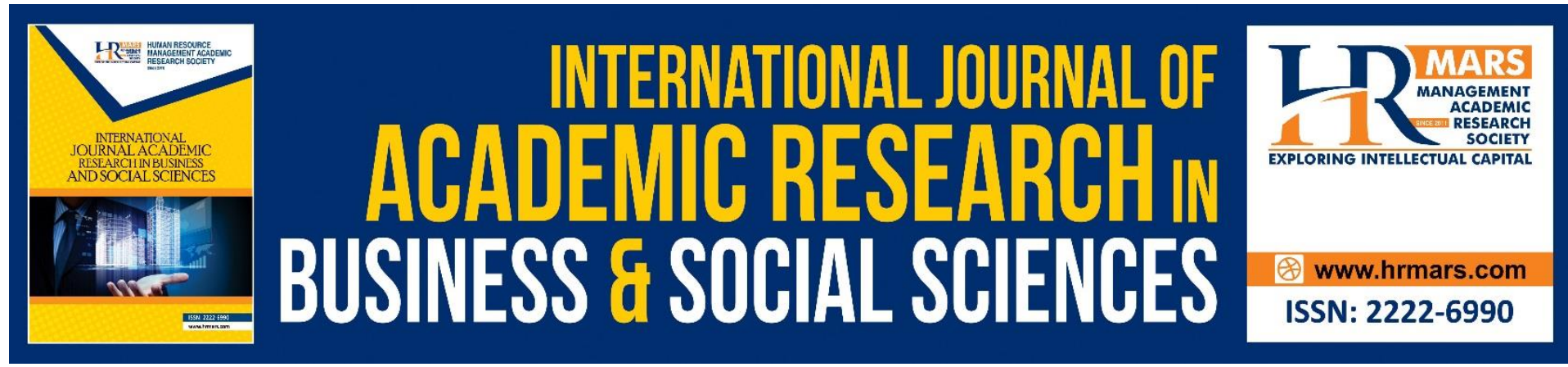

\title{
Levels and Causes of Stress, Anxiety and Depression among Road Transport Department Malaysia Headquarters Staffs
}

\author{
Wong, B. Y. \& Subhi, N. \\ Center for Research in Psychology and Human Well-Being, Faculty of Social Science and \\ Humanities, Universiti Kebangsaan Malaysia, 43600 Bangi, Selangor, Malaysia \\ Corresponding author: nas2572@ukm.edu.my
}

\begin{abstract}
The high levels of stress, anxiety and depression among government servants in Malaysia are alarming to all Malaysians. Previous studies have shown that stress, anxiety and depression strongly affect work performance and mental health. Furthermore, everyday people are experiencing stress from different situations including work and home but do not know the real cause and do not have the right way to deal with stress. Level of stress, anxiety and depression and the factors that influence it among the people of the Road Transport Department Malaysia (JPJ) are the main focus of this study. The study was conducted at the Road Transport Department Malaysia (JPJ) Headquarters. This study is a combination of studies using both quantitative and qualitative methods. For the quantitative method section, the survey was conducted on $600 \mathrm{JPJ}$ staffs but received only 239 questionnaire forms. For the part of the qualitative method, the researcher used semi-structured interviews to examine the stress factors among the respondents during the interview. A five-question set was used to interview eight respondents. The findings showed that all demographic factors such as gender, age, marital status, religion, education level, grade and job position were not significantly related to stress, anxiety and depression levels. In addition, the study also found that there are four main factors contributing to stress, anxiety and depression, namely family factors, health factors, workload factors and co-workers' factors. The researchers hope the findings of the study will help the JPJ authorities to design appropriate programs for the purpose of prevention and management of stress, anxiety and depression. In addition, the researcher also hope that the findings of the study could be used by the JPJ to review and develop a more friendly management system with the employees.
\end{abstract}

Keywords: Stress, Anxiety, Depression, JPJ, Staffs

\section{Introduction}

Stress, anxiety and depression are not new words but have been heard for a long time. Past studies have shown almost everyone experiences stress and anxiety from time to time to varying degrees (Timothy, 2017). Stress is the result of any demand placed on the brain or physical body. Individuals will feel depressed when a demand is more than the control of the brain or physical body. A situation that is too stressful may cause a person to feel frustrated. 
Anxiety is a feeling of fear, apprehension or restlessness. Anxiety is a response to prolonged stress especially from individuals who are unable to trace the cause of their stress. Although stress and anxiety are often associated with in a negative form but if it occurs in a short term and controlled it is able to provide a positive return. This is because short -term stress and anxiety can help individuals in overcoming challenges or dangerous situations. Examples of everyday stress and anxiety include worrying about finding work, feeling nervous before a big test, or being embarrassed in certain social situations. If an individual does not feel anxious, he or she may not be motivated to learn to do the things that needs to go through in life. However, if stress and anxiety begin to interfere with an individual's daily life, it may indicate a more serious problem. If an individual begins to avoid dealing with a situation due to irrational fears, constant worry, or severe anxiety, chances are that an individual can no longer control his or her stress and needs to seek help from a professional.

In Malaysia, Malaysians work about 15 hours a day on average, which is more than the contract hours set by the Malaysian government. These results have far surpassed contract working hours in Singapore, Hong Kong and Australia, but Malaysia is also one of the lowest in productivity (Econ, 2017). A study on the workplace conducted by AIA Vitality involving the four countries mentioned above found that workers in Malaysia bear too much workload, experience stress and lead unhealthy lifestyles. Therefore, workers in Malaysia are reported to have high risks in health and low productivity. Due to high stress and an inactive lifestyle, the study found that 84 percent of Malaysian workers reported having at least one health illness, while 53 percent were at risk for mental health problems.

The Star (2018) reported that 29 percent of Malaysians suffer from mental illness caused by stress. Further it reported that depression would be a major mental health disease among Malaysians by 2020 when more people are expected to experience higher levels of stress due to work and family stress. The report also reported an increase in cases of depression from 12 percent of depression cases in 2011 in Malaysia rose sharply to 29 percent in 2017, an increase of more than half in six years. Most people find it difficult to deal with the problems they face at work. The individual's stress becomes severe when the source of stress is related to problems from family members and has no other support. Stress is more easily experienced by individuals who find it difficult to share their feelings and frustrations. Therefore, the community needs to collectively tackle these diseases caused by stress and build effective prevention strategies as well as programs in managing mental health problems.

Stress or pressure is a modern epidemic and leads to public health concerns now. Mohd Shaiful, et al (2018) review the prevalence of occupational stress and the causes of its prediction among the Malaysian population. They found that the frequency of occupational stress incidents ranged from as low as 6.0 percent to 71.7 percent. The findings of the study also outlined the five most stressful jobs namely primary school teachers $(71.7 \%)$, prison officers (45.8\%), police (38.8\%), secondary school teachers $(34.0 \%)$ and finally university academics (22.1\%). Although the predictions vary by occupation but can be inferred through two dimensions namely organizational factors and individual factors. Among the organizational factors that cause employees stress are high job demand, poor workplace conditions, lack of organizational support, job insecurity, long working hours, career development burden and conflicts between employees. On the other hand, the individual 
factors that cause job stress are gender, age, marital status, number of children and strategies for coping with stress.

To confirm this Zukri \& Hassim (2010) also conducted a study on stress levels and ways to cope with stress among prison officers in Kedah, Malaysia. They indicated that the prevalence of stress among prison officers in Kedah was 45.8 percent. The prevalence of stress based on rank category showed that wardens had a higher prevalence of stress (55.2\%), followed by lower-ranking officers (34.3\%) and high-ranking officers (26.9\%). Prison officers are among the most stressful jobs in Malaysia, but many people still work as prison officers. It may be that they must work to cover the cost of living of the family. Conflict exists between a job you like and a job with lucrative salary. This research is in support to Cooper and Williams (1991) which indicated that blue collar workers are more exposed to health risk related to work as compared to the white collar and professional workers.

Comparatively, Haryati (2013) conducted a study on workers of a private sector related to work stress factors. The study conducted on 40 staffs MAINS Holdings Sdn. Bhd. Found that the most contributing factors to the stress experienced by the staff is the organizational structure factor followed by career and achievement factors, intrinsic factor, relationship at work, housework and work barrier factor. Overall, based on demographic factors, the results of the study found that there are no differences in work stress factors with demographics, namely gender, length of service and marital status except in terms of age, which is there are differences in work stress factors according to age. In conclusion, this is to show that not only public sector employees who experienced stress but private employees also experienced similar situation. In addition this finding also indicated that even religious based organization is also prone to stress.

Mariamdaran (2016) discussed the differences in the level of depression between remanded and sentenced prison inmates concluded that remanded prison inmates showed higher levels of stress compared to inmates who had been sentenced to depression. Prison inmates' anxiety about the court's decision and fear of the sentence to be handed down is a source of stress. On the other hand, inmates who have been sentenced experience less levels of stress because inmates have accepted and are aware of the length of time they need to spend in prison. Thus, the level of depression was found to be higher among remanded prison inmates compared to sentenced prison inmates.

It is not only the working class or adults who are stressed or depressed. Chong Hui, Sandhya, \& Rebecca (2018) stated that Malaysians aged between 13 to 17 years old suffered from mental health problems in critical and very worrying conditions. The study showed that one in five respondents (18.3\%) suffered from depression, two in five respondents $(39.7 \%)$ suffered from anxiety and one in 10 respondents (9.6\%) suffered from stress. The number of suicide cases is also very worrying among students. The author suspects that this phenomenon may be related to the education system in Malaysia where examinationoriented culture causes undue stress, not only affects students but also teachers. As a matter of fact, a study by Rathakrishnan et al. (2020) of teachers in Sabah concerning burnout indicated that 24.6 percent experienced high on emotion exhaustion, 8.85 percent experienced high on depersonalization and 64.9 percent experienced high on decrease selfachievements. Also in similar setting, a study on academicians in one of the research 
university in Malaysia found that of their respondents 4.5 percent experienced severe stress, 52.9 percent experienced anxiety and 35.4 percent experienced depression (Hassim \& Noor, 2016). Stress or job stress is an issue that is very common to hear not now but since time immemorial. Many previous studies have been done on the most stressed occupational groups previously mentioned but still no author has conducted a study on the staffs of the Road Transport Department Malaysia (JPJ). As a result, the researcher would like to survey the level of stress, anxiety and depression among the staff of the Road Transport Department Malaysia (JPJ) so that the authorities can prevent the occurrence of undesirable scenario in the future.

\section{Method}

This study administered mixed method approach combining both quantitative and qualitative methods. The combined method used in this study is to obtain information from various perspectives in order to meet the objectives of the study. For the quantitative method, the researchers used the online survey research method using Google Doc application. The questionnaire used consists of two parts, the first part is to obtain demographic information of the sample and the second part comprised of the Depression, Anxiety and Stress Scale (DASS) questionnaire. This is to examine the level of stress, anxiety and depression of the staffs in Road Transport Department Malaysia (JPJ). The survey was distributed to 600 respondents consisting of JPJ headquarters staffs from different divisions. However, only 239 questionnaires were successfully returned for analysis purposes.

As for the qualitative method, the researchers used semi-structured interviews to examine the stress factors experienced by respondents in the workplace. A set of interview protocol was constructed containing five questions was used to interview a total of eight respondents. Respondents were selected based on the results of the survey made online as part of the quantitative study. Only respondents who were at severe and very severe levels in the stress, anxiety and depression scale were selected to be respondents for the qualitative method section. All the names used in this study is pseudonyms.

\section{Results}

Table 1 shows the frequency and percentage according to stress level. There are five levels of stress selection namely normal, mild, moderate, severe and very severe. The majority of respondents comprised of 217 respondents (90.8\%) showed a normal level of stress, 14 respondents $(5.9 \%)$ were at a mild level, five respondents (2.1\%) showed a moderate level, two respondents $(0.8 \%)$ at a severe level and one respondent $(0.4 \%)$ was at a very severe level.

Table 1: Frequency and percentage according to stress levels

\begin{tabular}{lll}
\hline Stress Levels & $\begin{array}{l}\text { Frequency } \\
(\mathrm{n})\end{array}$ & $\begin{array}{l}\text { Percentage } \\
(\%)\end{array}$ \\
\hline Normal & 217 & 90.8 \\
Mild & 14 & 5.9 \\
Moderate & 5 & 2.1 \\
Severe & 2 & 0.8 \\
Very Severe & 1 & 0.4 \\
\hline Total & 239 & 100.0 \\
\hline
\end{tabular}


Table 2 shows the frequency and percentage according to anxiety level. There are five levels of anxiety selection namely normal, mild, moderate, severe and very severe. The majority of respondents comprised of 163 respondents (68.2\%) showed a normal level of anxiety, 39 respondents (16.3\%) were in the mild level, 27 respondents (11.3\%) in the moderate level and five respondents each $(2.1 \%)$ in both severe and very severe levels.

Table 2: Frequency and percentage according to anxiety levels

\begin{tabular}{lll}
\hline Anxiety Levels & $\begin{array}{l}\text { Frequency } \\
(\mathrm{n})\end{array}$ & $\begin{array}{l}\text { Percentage } \\
(\%)\end{array}$ \\
\hline Normal & 163 & 68.2 \\
Mild & 39 & 16.3 \\
Moderate & 27 & 11.3 \\
Severe & 5 & 2.1 \\
Very Severe & 5 & 2.1 \\
\hline Total & 239 & 100.0
\end{tabular}

Table 3 shows the frequency and percentage according to depression levels. There are five levels for depression selection namely normal, mild, moderate, severe and very severe. The majority of respondents comprised of 199 respondents (83.3\%) showed a normal level of depression, 27 respondents (11.3\%) were at a mild level, six respondents $(2.4 \%)$ were at a moderate level, four respondents (1.7\%) were at a moderate level severe and three respondents $(1.3 \%)$ were in a very severe stage.

Table 3: Frequency and percentage according to depression levels

\begin{tabular}{|c|c|c|c|}
\hline Levels & Depression & $\begin{array}{l}\text { Frequency } \\
\text { (n) }\end{array}$ & $\begin{array}{l}\text { Percentage } \\
\text { (\%) }\end{array}$ \\
\hline & Normal & 199 & 83.3 \\
\hline & Mild & 27 & 11.3 \\
\hline & Moderate & 6 & 2.4 \\
\hline & Severe & 4 & 1.7 \\
\hline & Very Severe & 3 & 1.3 \\
\hline & Total & 239 & 100.0 \\
\hline
\end{tabular}

\section{Contributing Factors to Stress, Anxiety and Depression}

The qualitative section involves eight respondents who are members of the JPJ Headquarters that have worked for five years and above. The findings of the study summarize the causes that contribute to stress, anxiety and depression into four factors: (1) health, (2) family, (3) workload and (4) relationships with colleagues.

\section{Health}

In this study, health is one of the issues that cause respondents to feel stressed. Respondents' health problems greatly interfere with daily activities, including work. Sometimes they have to take sick leave because their health does not allow them to work. For example, Mrs. Rose was diagnosed with depression and anxiety by a doctor. As a result of these diseases, she has to take medicine but the medicine often makes her feel tired and powerless to get up and carry out daily activities. In addition, she also often needs to go to the hospital for follow-up treatment as well as the need for medications which often takes a long time; 
The doctor said I had depression and anxiety. The doctor gave me a lot of medicine. I don't like taking medicine because I can't get up tomorrow. I want to go to work but I can't get up. I don't want to take medicine. When I don't go to work, other people talked about me. It's not that I don't want to go but I just don't have the strength. I also have to always visit the hospital to take medicine and see a doctor. It's not short [the hospital visits], sometimes you have to wait for hours. Other people don't understand me.

For Mr. Kamarul, his health problems have made him no longer able to drive. He stated that every time he wanted to drive, he would feel short of breath as well as feel like defecating. This problem caused him to depend on his wife to go anywhere including to work and this caused him to feel inferior;

I have driving problem. I can't drive now. The time I drive I will feel short of breath as well as feel like defecating. I used to drive all around Malaysia. Can you can imagine...? Before there is no Waze, no maps but I can drive anywhere. Now going to work, my wife has to send me. I feel like I'm really useless.

In addition, they are often labeled as patients also causing them to feel depressed. The stigmas of such society make them feel inferior and do not dare to meet new people. They also feel unappreciated. For example, Mrs. Rose said, "They always say I'm crazy. I'm so embarrassed. I only have one friend. But my friend is always teased by her friends, why does she wants to be friends with me?"

\section{Family}

A happy family is a family that is able to solve family problems by discussing or solving them in a good way. Family members should also understand each other. Everyone in this world expects a happy family but not everyone can enjoy a happy family. Past studies have shown that conflict in the family can interfere with work performance. These findings are in line with the results of interviews that have been conducted. Among the factors related to the family theme is the issue of offspring or children. For couples who have established a household, having children of their own is still seen as a must for most communities, including in the local context. The pressure will certainly increase with the number of years that the marriage have been established. For example, this has been shared by Mr. Faisal who stated that he often feels depressed considering that after eight years of marriage he still has not had children. The impact is that sexual intercourse with his wife is getting bland and more stressful for him;

I have been married for eight years but with no children. I understand a child is a blessing from God, but it's a lie if you say I'm not stressed when other people ask me why my wife is not pregnant. My wife and I have always tried to have children to the extent of being forced into making love. The more forced, the more unpleasant it feels. Now, I only feel stressed when my wife asks me to have $[$ sex]...

Apart from the offspring factor, the marital relationship factor which involves understanding and communication is also very important. If this issue is not addressed properly it will definitely lead to various problems arising. For example, Mr. Tan stated that his wife, a 
housewife, often nags every time he comes home from work. This made him lose focus on work and eventually forced him to live separately from his wife; "My wife doesn't work, just expect my salary. Always nags me, can't stand it you know? I can't focus on work if she's making noise. That's why now I moved out of the house, fed-up to look at her face. "

Sometimes stress can also come from the family even indirectly. This happened to Mr. Mawi where if he returned to his village then someone would ask him or his family about his marital status or with the question, "When do you want to get married?" This made him stressful in addition he pity his mother and father who had to answer the question on his behalf;

I need to take care of my father's and mother's pride. I am 40 but not married yet. When I go back to the village, they asked me when I wanted to get married, I didn't know what to answer.

On the other hand, Mrs. Farra got married at the insistence of her family. She admits that when she was single she carried the image of a pengkid [female transgender]. However, she made the decision to get married on the basis of the family's insistence of her to get married and in addition to avoiding her mother's constant nagging. The good and responsible nature of her husband makes her more stressed because she is often haunted by guilt towards her husband;

I used to be a pengkid [female transgender], my parents were just worried about me. Now that I'm married, my mother is still not satisfied, she still wants to restrain me. Sometimes I feel sorry for my husband. It's not that I don't love him, he's good but I have no feelings. I hold on because I don't want mum to nag. I got married before because I couldn't stand my mother's nagging. My husband sends me to work every day because we work at the same place. My husband is a good person, I feel so sorry for him that makes me stressed up. I always think, "Am I doing the right thing?"

\section{Office Workload}

Workload is a number of processes or activities that must be completed by an employee in a certain period of time. If an employee is able to complete and adapt to a given number of tasks, then it does not become a workload. On the other hand, if the employee does not successfully complete the tasks entrusted to him or her then it will turn into a workload. Road and Transport Department Malaysia (JPJ) is an agency that has been established for a long time and has a established working system. However, stress, anxiety and depression occur when an individual is unable to complete his or her work because he or her has to bear the work of others. This was narrated by Mrs. Khai voicing the problem of bearing the work of her colleagues;

I have a lot of work to do, especially at the end of the month because I am in the finance department. Every month you have to send off the account. Now I have to bear the work of my friend who is on maternity leave. Lots of work but don't get any benefits, the salary stays the same. At the moment I'm the only one now, everything I have to do. To the extent that I couldn't take an early off for Eid then because I wanted to finish work, how could it not be stressful. 
At the same time, Mrs. Rose also voiced the workload experienced where her position is shared by several units in the department. The many tasks plus majority that required urgency made her often depressed;

I have the lowest rank in JPJ. I'm shared between several units. My job is to type letters, distribute letters and more. I don't just have to handle one but three units. This boss gives work, that boss gives work, everyone wants it urgent. Just try to understand that I also need to rest. Try to give work one and a time and not all at once...

\section{Relationships with Colleagues}

For working individuals, a lot of time is spent in the office which is at least eight hours a day. As such, co-workers are the individuals who spend the most time together on a daily basis when compared to others. Harmonious relationships between co-workers can help employees increase job satisfaction and reduce stress. Means of good communication plays an important role in maintaining harmony in the office. The trust factor is also very important in maintaining a harmonious situation. However, Mr. Tan and Mr. Mawi showed distrust to their colleagues causing them to feel depressed. For Mr. Tan, he felt that most of his friends at work only spoke nicely in front of him while behind him they often said differently. Thus, in his opinion this matter had prevented him from having the opportunity of promotion;

I don't believe everyone around me. The front of me they speak kindly, at my back they back stab. That's how I didn't get promoted. I want to throw up when I look at their faces. Now I am only close with a few people. I don't care about other people.

For Mr. Mawi, he felt that there are people who used black magic against him given the change he experienced from being someone who likes to be active to someone who has no interest in doing anything. As a result, he no longer trusts his colleagues in the office;

I always felt there is someone using black magic on me. I don't trust them anymore. Besides, I can't comprehend why I used to like doing things but now I don't seem to be interested in anything. I can't trust people in this office, they like to play behind my back.

Unlike Mrs. Farra, she felt depressed with co-workers due to the new image she brought with her after marriage. She used to carry the image of a pengkid (female transgender) but after getting married she was wearing a baju kurung (a traditional Malay woman attire) and long hair. However, she admits that her smoking habit is still insurmountable and this further worries her as from the general view this habit is not in line with the image she carries now;

I used to be a pengkid [female transgender]. I don't know if people now can accept me. Now I'm wearing a baju kurung, and I have long hair. I'm not sure about my look now, I feel like I'm not good at make-up. That's why I don't want to hang out too much with other people. I'm often anxious, so I'm stressed. After all, I am a smoker, a female smoker, definitely other people can't accept me... 


\section{Discussion}

This study was conducted aimed at exploring the levels of stress, anxiety and depression and the causes that contributed to it. There are many previous studies conducted on stress and how to manage it, but the majority of studies have only focused on other agencies. Therefore, this study was conducted to fill the gap in which to study in detail what are the causes of stress, anxiety and depression among the staffs at the Headquarter of the Road Transport Department Malaysia (JPJ). Overall, the results of this study indicated the level of stress, anxiety and depression at the level of severe and very severe are 1.2 percent, 4.2 percent and 3.0 percent respectively. Although the percentages are small, it is worth to take necessary action in curbing the situation to avoid worsening condition in the future. The results of the study also have summarized the four main themes that cause stress, anxiety and depression to the respondents, namely health factors, family, workload and relationships with colleagues.

Based on the study, one of the main cause of stress, anxiety and depression among JPJ staffs is health factor. Among the eight respondents interviewed, there were four respondents with mental illness. Although only two respondents were receiving medical treatment at the point of the interview conducted. Furthermore, the other two respondents did not show positive development. Mentally ill patients need regular treatment like they always need to visit a doctor, counselor and seek supportive care other than a doctor. Therefore, they often have to take sick leave to see a doctor. In addition, they are also very dependent on his condition every day to attend work. For example, an individual who has trouble sleeping because of the effects of medication finds it difficult to wake up early the next day. Such things will interfere with the work performance of employees because they are often unable to attend work. This study also provides information to the researchers that most likely the staffs of the Road Transport Department Malaysia (JPJ) do not want to admit that they face stress for fear of society's stigma. This is because, the JPJ Counseling and Psychological Wellbeing Services Unit (UKS) will call individuals who are identified as experiencing stress to conduct counseling sessions. Although this act is noble however, the negative connotation counseling has been associated with the organization has given the impression that "only people with problems need counseling." Therefore, JPJ staffs do not want to admit that they are stressed for fear of being called to a counseling session and being labelled problematic.

The second factor is family factor. Respondents experienced a stressful situation at home that brought this situation to work. Job performance also showed a decline. From this study among the issues that lead to depression are having difficulty of having children of their own and interpersonal problem with their spouses. This means that employees needed to be taught on how to separate family and work matters. This can be done through talks and workshops which can be schedule periodically. Furthermore, the counseling services can be reintroduced as a positive support system for all to benefit from in order to gain healthier lifestyle and wellbeing.

The third factor is the workload factor. JPJ is an agency that serves the public. Therefore, the work done must be completed within the specified time. Every job is done by a different person. If a person is on leave, the other person has to take responsibility for the person who is absent. Increased workload causes dissatisfaction in the workplace. In addition, the government is experiencing economic problems. As a result, many positions could not be filled 
due to lack of budget. Therefore, other employees have to take over the duties of the unfilled position. These issues will cause stress in the workplace. Similarly, Tan (2013) found that their samples of trainee doctors experience higher percentage of abnormal anxiety as compared to normal anxiety on the issue of performance pressure.

The last cause is the relationship factor with co-workers. Some respondents showed distrust of other colleagues. Colleagues are individuals who most often meet other than family members as it is necessary to meet daily for at least eight hours for a period of many years. If trust does not exist between co-workers, then the work environment is disharmonious as they will do the work with much suspicion, experiencing fear of being persecuted which lead to feeling of unhappiness most of the time at work. In the end, group spirit is unattainable and indirectly work performance is affected. In line with this finding, Phoon (2006) found that the relationship between trust-in-supervisor and helping coworkers was dependent on the level of perceptions of organizational politics. This means that the more trust employees put upon their supervisors the more they are willing to help their coworkers, however, this is only true if the perceived organizational politics is low. Employees in a working in a highly perceived organizational politics believed that they cannot ascertain the time and effort spent in helping their coworkers will be duly rewarded thus to them it is best to concentrate on their own interest and welfare.

\section{Conclusion}

The findings of the study showed the level of stress, anxiety and depression are considered low and still under control. Nonetheless, it is beneficial to take early necessary intervention to curb the issues to avoid future problems. The findings also show four main factors that contribute to the level of stress, anxiety and depression, namely health, family, workload and relationship factors with colleagues. Since the JPJ Counseling and Psychological Wellbeing Services Unit (UKS) has already been set up, it is wise to relook on the image and the efficacy of the services given. UKS needs to be looked upon as an outlet that support and assist its client in acquiring happier working condition which leads to healthier lifestyle.

\section{References}

Chong, H. L., Sandhya, M., \& Rebecca, R. (2018). Too Many Teens Suffering from Stress. Malaysia: The Star.

Econ. (2017). Malaysian Workers are "Most Stressed". Petaling Jaya: The Star.

Hans, S. (1976). The stress of life (Rev. ed.). New York: McGraw-Hill.

Haryati, K. (2013). Faktor tekanan kerja dalam kalangan kakitangan MAINS Holdings Sdn. Bhd. FASS Final Project (Psychology). Open University Malaysia. Unpublished.

Mariamdaran, S. D. (2016). Comparison of depression between remanded and sentenced inmates. Journal of Advanced Research in Social and Behavioural Sciences, 3(1), 72-78.

Mohd, S. A. K., Azniza, I., \& Rosnah, I. (2018). A review of occupational stress prevalence and its predictors among selected working populations in Malaysia. Malaysian Journal of Public Health Medicine, 18(2), 1-6.

Mohd, Z. I., \& Hassim, N. I. (2010) A study of occupational stress and coping strategies among correctional officers in Kedah, Malaysia. Jurnal Kesihatan Masyarakat, 16 (2). 66-74.

Noor, H. I., \& Arma, N. (2016). Occupational stress and its associated factors among academician in a research university, Malaysia. Malaysian Journal of Public Health Medicine, 16(1), 81-91. 
Poon, J. M. L. (2006). Trust-in supervisor and helping coworkers: Moderating effect of perceived politics. Journal of Managerial Pscyhology, 21(6), 518-532.

Rathnakrishnan, B., George, S., Bikar Singh, S. S., Rahim, M. K., Amin, M. W. (2020). Burnout among secondary school teachers in Malaysia, Sabah. Journal of Xidian University, 14, 1530-1536.

Star, T. (2018). 29 peratus of Malaysians have mental problems due to stress, says Lam Thye. https://www.thestar.com.my/news/nation/2018/08/05/lee-lam-thye-more-msianswill-suffer-from-depression-by-2020-due-to-stress\#tPshtH8r4tKiwlJ6.99 [6 January 2022].

Tan, S. M. K., Jong, S. C., Akmal, N. J., Shahirah, N. J., \& Azhar, S. (2013). Physician, heal thyself: The paradix of anxiety amongst house officers and work in a teaching hospital. AsiaPacific Psychiatry, 5, 74-81.

Timothy, L. (2017). Stress and Anxiety. Retrieved from Healthline: https://www.healthline.com/health/stress-and-anxiety [2 January 2022]. 